\title{
AN INFORMATION SYSTEM OF PREDICTIVE MAINTENANCE ANALYTICAL SUPPORT OF INDUSTRIAL EQUIPMENT
}

\author{
Andrey I. Vlasov ${ }^{1,2^{*}}$, Vladimir V. Echeistov' ${ }^{1}$, Aleksey I. Krivoshein ${ }^{1,2}$, Vadim A. Shakhnov' ${ }^{1}$ Sergey S. Filin ${ }^{2}$, \\ Vladimir S. Migalin ${ }^{2}$ \\ ${ }^{1}$ Bauman Moscow State Technical University, Russian Federation \\ ${ }^{2}$ LLC "Konnekt", Russian Federation
}

The work considers the stages of design and operation of the information expert system of predictive maintenance analytical support of industrial equipment exemplified by vacuum devices. Special attention was paid to the study of the methods of maintenance of the equipment and also to the development of a concept of a modern system of predictive maintenance. The formalization of the test system of predictive maintenance was performed in the package MS Excel using the programming language Visual Basic for Applications. The result of work is the development of an automated expert system of analysis of the methods and means of predictive maintenance of vacuum devices. The particular results were obtained with the support of the Ministry of Education and Science of the Russian Federation within the project of the Agreement No. 14.579.21.0142 UID RFMEFI57917X0142.

Key words: Predictive maintenance; Data transfer; Maintenance; Defects prediction; MS Excel; VBA.

\section{INTRODUCTION}

The work is dedicated to the research of means and methods of the predictive maintenance systems of industrial equipment exemplified by vacuum devices. The object of research is the automated expert system of analysis of methods and means of predictive maintenance. The relevance of work is determined by the necessity to develop and implement a system of equipment predictive maintenance at the radiotechnical enterprise to minimize the costs for maintenance of the enterprise and to increase of output due to minimization of the equipment downtime.

The systems of predictive maintenance allow achieving the following values:

- a reduction of equipment downtime;

- a decrease in costs for equipment repair;

- a decrease in the number of unscheduled repairs;

- trouble control of operating modes;

- an increase in the efficiency of enterprise management.

The objective of this work is to develop an automated expert system of analysis of methods and means of predictive maintenance of vacuum assemblies in the package MS Excel using the programming language Visual Basic for Applications.

The considered system shall solve some problems related to the operation of the industrial equipment: liquidation of emergency situations at the manufacturing site; online diagnostics of modules, components and assemblies.

To achieve the stated objectives, it is presupposed in the work to solve the following set of problems:

- classification of repair methods;
- development of a concept of a predictive maintenance system;

- development of an expert system of analysis of methods and means of predictive maintenance.

Methods used for solution of the set problem:

- elements of theory of functional simulation systems, software tools of CAD system, design and engineering bureaus in CAD system of electrical systems, expert systems in the economy;

- methods of reengineering and project management within the integrated MICS;

- methods of information system design using the programming language Visual Basic for Applications.

The result of work is the developed automated expert system of analysis of predictive maintenance of vacuum devices. Maintenance takes the significant part of costs at any industrial enterprise: from 15 to 60 percent of an item cost [1].

\section{REVIEW OF LITERATURE}

Currently, maintenance [1] is divided into reactive maintenance, preventive maintenance and predictive maintenance (see Figure 1).

Maintenance in the case of a failure or as it is also called reactive maintenance follows the simple philosophy: repair is performed only in case of failures or breaks [2]. It is not reasonable as it leads to significant economic losses caused by the repair of the equipment and downtime of other production facilities.

Preventive repair reflects the opposite situation in comparison with the previous method, the philosophy that is aimed to the repair before the failure or break [3]. The European standard of technical maintenance of the industrial equipment [4] determines this type of repair 
as the technical maintenance performed according to the set intervals or to the prescribed criteria and designed to reduce the probability of a failure or deterioration of the item functioning. That means that in the most cases the engineering personnel that maintains the assembly has to rely upon the data from the manufacturer who estimated the intervals between the maintenances using mathematical statistics. The policy of preventive repair is not convenient from the economic point of view because maintenance actions are scheduled regardless of the deterioration of every equipment element separately. Actually, every component belonging to the same unit can deteriorate differently due to the inevitable physical distinctions and especially in different operating or ecological conditions [5].

Currently, manufacturing companies gain experiences in production in networks and smart logistics and de-

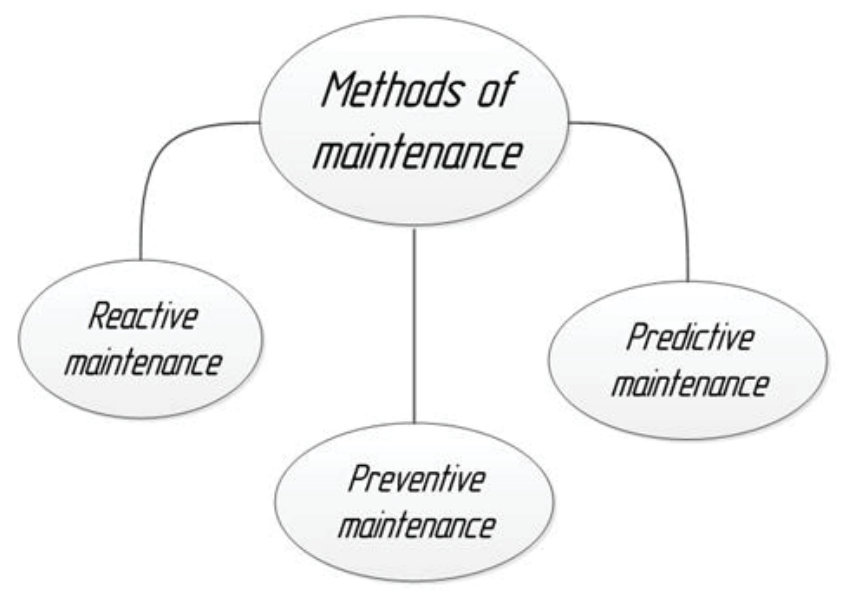

Figure 1: Classification of maintenance methods

velop new organizational structures and business models which better benefit from the new technologies and which adapt faster to the rapidly changing network environments [6-7]. As the information technologies develop, the implementation of various approaches to equipment maintenance becomes more popular. Assemblies usually show the signs of the approaching failures before they occur; therefore, while monitoring one can detect the actual condition of the assembly or its element. For example, the analysis of vibrations can provide the earlier diagnostics of deviations and later it can help detecting these failure mechanisms before the assembly condition reaches the alarm level. Supported by the time diagrams and frequency spectra, it is possible to use complicated statistical methods to process the information that will be used as initial data for decision-taking. Nevertheless, the policy of productive repair is not just monitoring of the equipment condition because using the predictive maintenance systems it is possible to predict the further behavior of the equipment [8]. Predictive maintenance systems are also called systems of intellectual diagnostics and predictive analysis; it is related to the fact that in such systems the solutions based upon the artificial intellect are widely used. Several modern methods of development of predictive maintenance systems are distin- guished; the most popular of them are shown in Figure 2. The method of development of a predictive maintenance system based upon the autoregressive model uses the

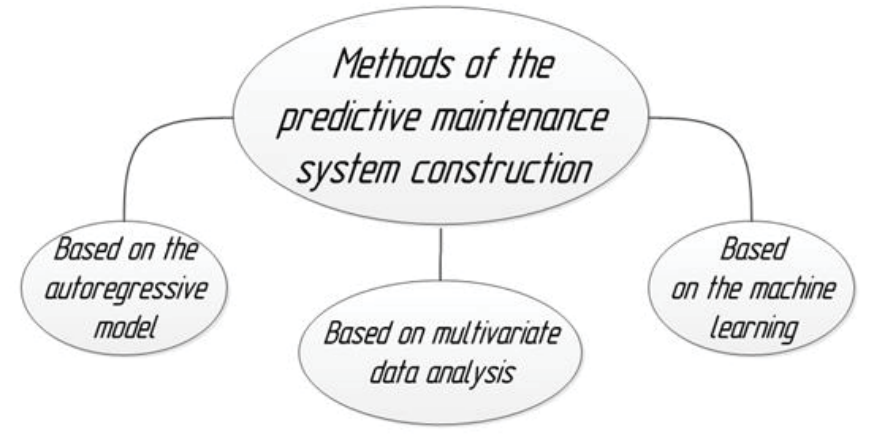

Figure 2: Methods of development of predictive maintenance systems

mathematical apparatus of analysis and prediction of the stationary time series in mathematical statistics making it possible to build the prediction of one or another characteristic, the statistics of which was transmitted into the system [9].

The model on the basis of multivariant analysis uses multidimensional data analysis allowing forming several variants of the further development, the combination of which allows obtaining a highly precise forecast of the further condition of the equipment [10].

The systems based upon the computer-aided learning model allow revealing the failures and evaluating the further service life depending upon the statistical data.

Within the framework of this work, the system of the latter type was realized as the model of computer-aided learning complies most completely with the specific character of the problems being solved.

\section{MATERIALS AND METHODS}

The system of predictive maintenance is based upon the Enterprise Resource Planning, Manufacturing Execution System, systems of technical maintenance and repair and also any other systems storing information from the sensors, information about repairs, and external factors (humidity, temperature, etc.). The key advantage in this case is that the system follows the evolutional direction of development of an information system of a large science-based company due to the use and addition of the existing engineering infrastructure of the industrial facility. The accuracy of prediction depends upon the filling of the system (data volume): the bigger the volume of empiric information, the more successful solution can be formulated basing upon the knowledge of the expert system.

The system of predictive maintenance consists of two main modules: the module of failure search in the equipment operation and the prediction module that estimates the non-failure operation time of a structural element or the equipment in general.

The module of failure search allows monitoring the con- 
dition of the equipment in a real-time mode for the occurrence of emergencies and emergency operation modes like it is done in the Computer-Aided Process Control Systems. Later the information is provided immediately to the engineering personnel; that is how the basic principle of intellectual diagnostics is realized.

The module of predictive maintenance predicts the condition of assemblies and is trained when receiving feedback from engineers and process engineers. This module allows revealing the condition of a structural element during a particular period of time before taking decision on repair or disposal of the equipment. Prediction helps take a decision on the future of the equipment and to schedule the repair plan on the base of the actual and predicted condition; that adds the elements of artificial intellect to the system due to highly efficient computer-aided learning: engineers and branch experts form the knowledge base for every particular system. For example, according to the plan it is necessary to remove the assembly out of service for repair in half a year but earlier the system of predictive maintenance detected the periodic temperature rise above the normal value and basing upon the obtained data it makes the prediction of the further operation in these conditions using the statistical data and knowledge base: will the defect reveal itself in such case or will there be a failure and how soon. Thus, the main task of predictive maintenance is the correct formation of a repair program regarding the current and predicted condition of the equipment.

The system is capable to obtain additional learning from branch experts and engineers, whose experience is digitated, added to a knowledge base and used for analysis. For example, when the structural element is broken or in case of the abnormal operation mode of the equipment, the reason can be revealed and the strategy of further actions can be developed basing upon the prediction of the residual resource. For this, the expert knowledge is required; experts explain the reason of the problem, and then this knowledge is used for training of the expert system to cover as many events and states of the studied objects as possible.

The short-term benefits are seen during the first days of work: the optimization of planning regarding the order of the required spare parts and materials for repair of the equipment, a decrease in the number of unscheduled repairs, a decrease in costs for equipment repair, control of breaks of operating modes. The key long-term effect is the change of the repair norms; that means the repair basing upon the condition of the equipment, and not because of failures or within the framework of the scheduled technical maintenance. Thus, one can exclude accidental alarms and increase the reliability of the equipment and the profitability of the enterprise due to the exclusion of the downtime for the elimination of serious failures and saving funds for expensive repairs.

In general, the system of predictive maintenance allows solving some relevant current problems:
- monitoring of the forecasted and technical state of the enterprise in the real-time mode;

- $\quad$ displaying of events and accidents arising during operation of the equipment;

- formation of the failure probability and residual resource of the equipment, which provides the possibility to perform preventive actions by maintenance specialists;

- introduction of the processes of technical maintenance of assets based not upon the maintenance regarding abnormal situations but upon maintaining the assets in good condition.

The application of predictive analytics at industrial facilities allows decreasing the downtime, distributing the material and technical resources for repair and maintenance in advance, accepting the timely managerial decisions regarding the removing of the equipment out of operation to prevent accidents [12-14]. Thus, the processing of the statistical operating data increases the operating stability, operating efficiency of the enterprise and the level of technical readiness [15-25]. Similar results were demonstrated in other empirical studies - in the field of technical safety of vital systems [26]; when assessing risk [27]; in various configurations of productions [28].

Using the concept of predictive maintenance system, the offered generalized structure is shown in Figure 3.

The algorithm of work of the predictive maintenance system provides the collection of statistical data, its process-

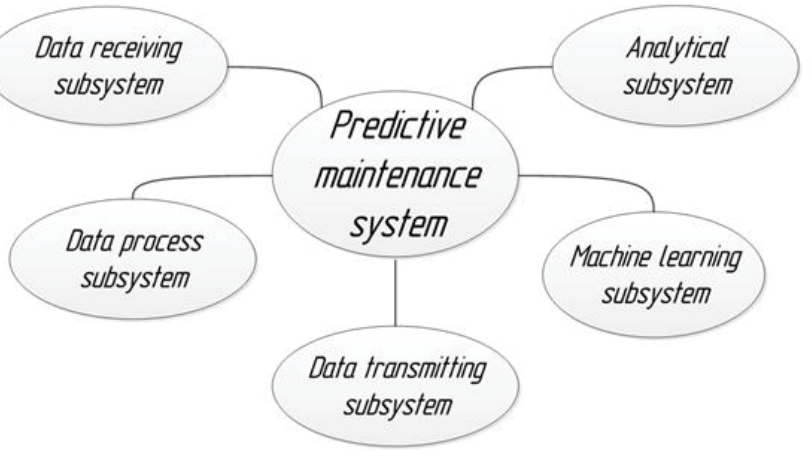

Figure 3: Structure of the predictive maintenance system

ing, analysis and development of a strategy, visualization of information and system training. The archive data and real time data are transmitted into the analytical system and are studied constantly by the expert system to determine the emergencies. Then the estimation of the current state and residual resource of the studied engineering object is performed with the following informing of the engineering personnel using the visualization system. Figure 4 shows the system algorithm that determines the sequence of start of the predictive maintenance system together with the maintained vacuum system.

The represented approach to the realization of an infor mational intellectual support system of predictive maintenance allows providing: 


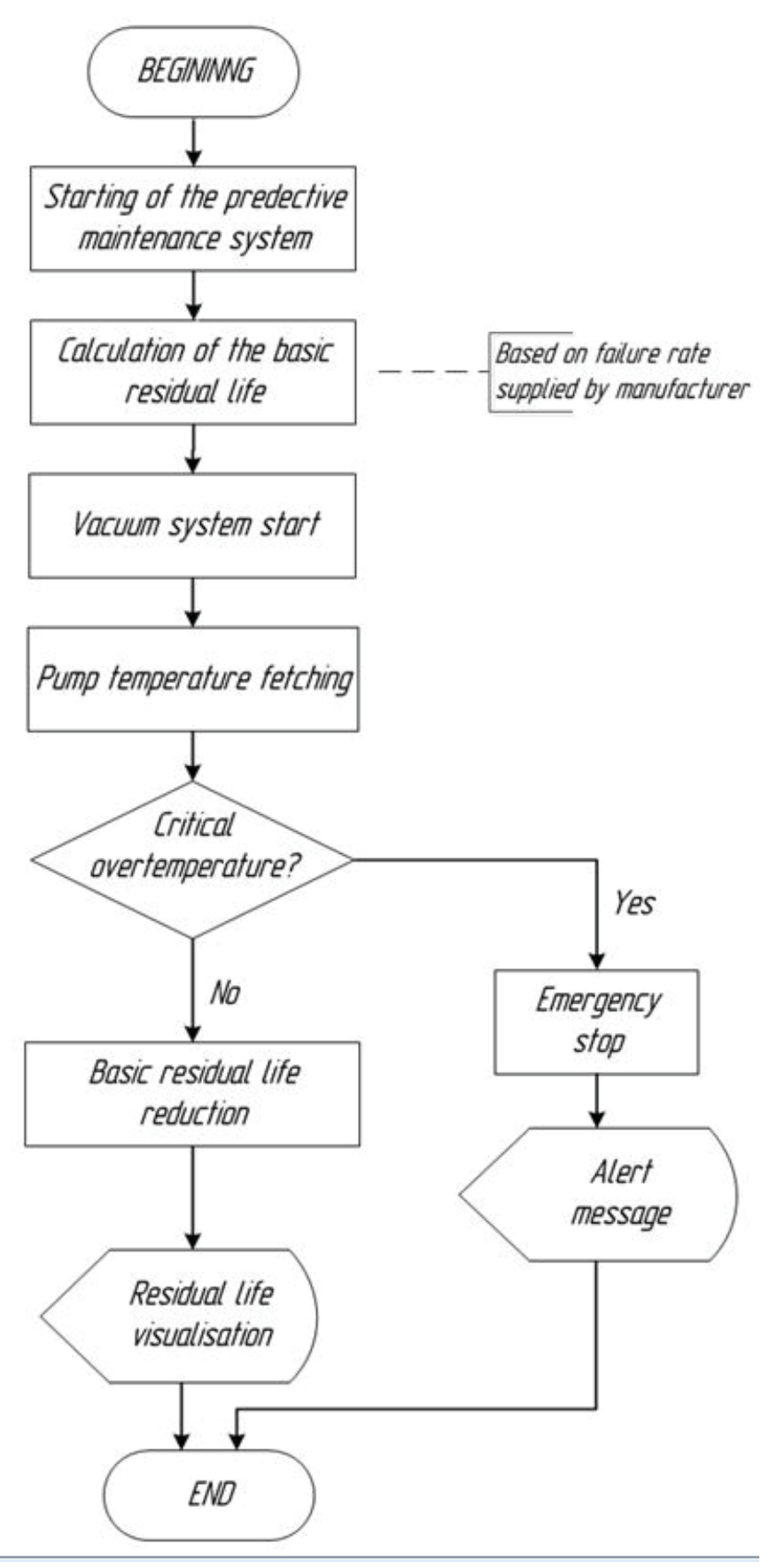

Figure 4: System algorithm

- a reduction of downtime of equipment;

- a decrease in costs for repair of equipment;

- a decrease in the number of unscheduled repairs;

- control of breaks of operating modes;

- an increase in the efficiency of enterprise management.

The minimally allowed set of system data includes the statistical operation data of the equipment and experience of the branch experts included into the knowledge base.

At the first stage, the predictive system, its initialization and estimation of the initial parameters are started (calculation of the basic residual resources). Later the maintained vacuum system is activated; the temperature of the power circuit is constantly monitored. In case of temperature growth above the allowed value, the system additionally reduces the residual resource of the assembly. In case of the high growth of temperature during a short period of time, the system performs the emergency shutdown.

Let us consider the peculiarities of the expert system of analytical support of the functions of predictive maintenance exemplified by the predictive maintenance of vacuum devices.

\section{RESULTS AND DISCUSSION}

The developed automated expert system of analytical support of the predictive maintenance (hereinafter referred to as the System) is realized in the package MS Excel by means of macros using the programming environment Visual Basic for Applications. Figure 5 shows the appearance of the system interface.

The system consists of three main activities (sheets):

- $\quad$ "Predictive maintenance system" is the main operating field which displays the main information of the equipment activity;

- "Temperature sensor values: is a sheet with data of the temperature mode of the equipment operation;

- $\quad$ "Log file" is a page with the error messages.

The first clause of the sheet "Predictive maintenance system" contains the information of the equipment failures intensity. The equipment intensity data are provided by the manufacturer and as seen from the Figure 2.1, they demonstrate the failures curve for the devices that passed the preliminary running. Using the failures curve, one can calculate the residual resource of the system setting the threshold value of the failure intensity.

According to the recommendation of the leading specialists in the field of the reliability theory, let us take the value $0.051 /$ hour as a threshold value [1]. At the set threshold value, the resource of the assembly will be 8 hours $(28,800 \mathrm{sec})$, which is specified in the second clause of the main operating field. Figure 6 shows the third clause of the main operating field.

This area of the main operating field is responsible for the system control, visualization of the operating parameters and warning of emergencies. The button "RESET" deletes the log file and brings the system to the initial state. Pressing the button "START" activates the system. According to the temperature data, the residual resource is calculated at every set moment of time as well as the emergency shutdown tangent, time from the start and also the current temperature increase.

The residual resource of the assembly operation is calculated according to the following formula:

$$
\text { r_res_1 }=\text { r_res_0 }-\mathrm{k} \_1 \cdot \Delta \mathrm{t}-\Delta \mathrm{t}
$$

where r_res_0 - previous value of residual resource, sec; $k \_1$ - conversion factor of residual resource; 


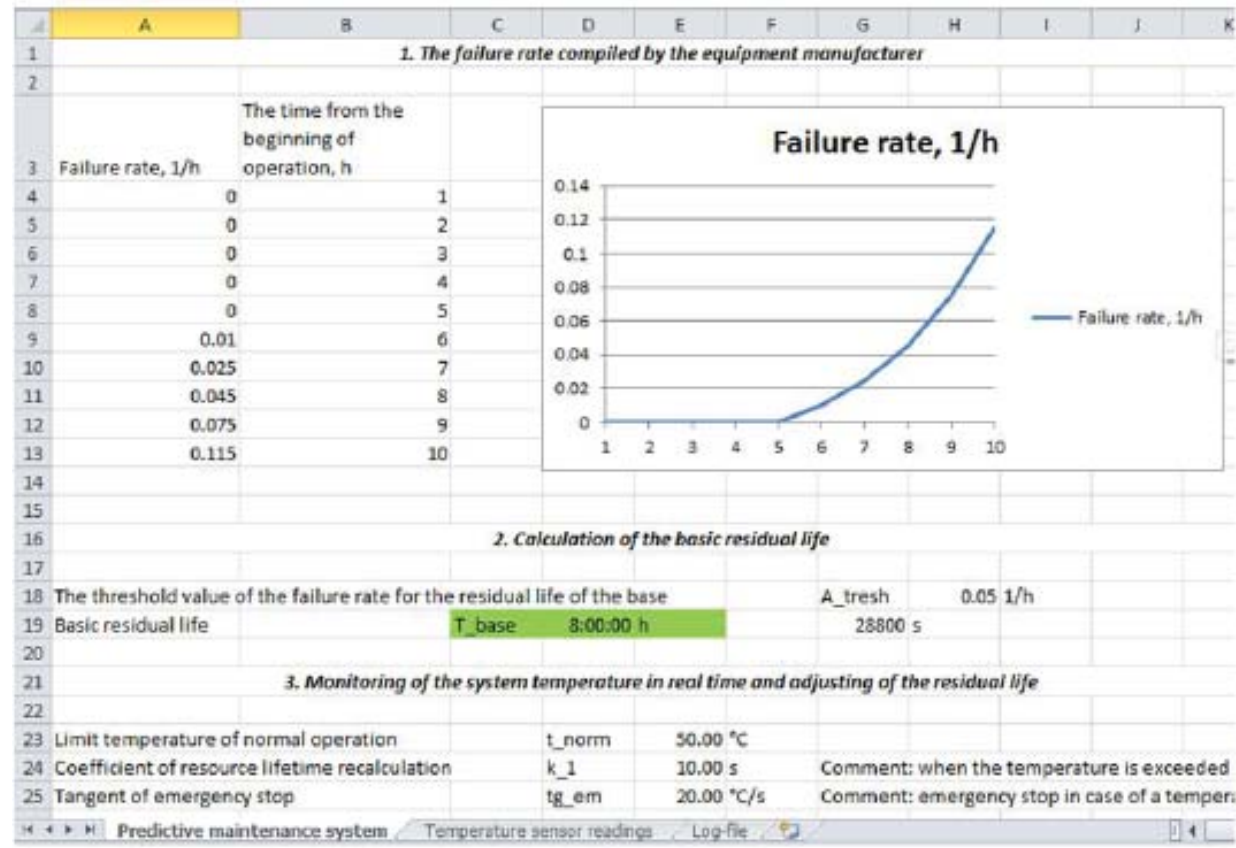

Figure 5: Interface of the expert system of analytical support of predictive maintenance

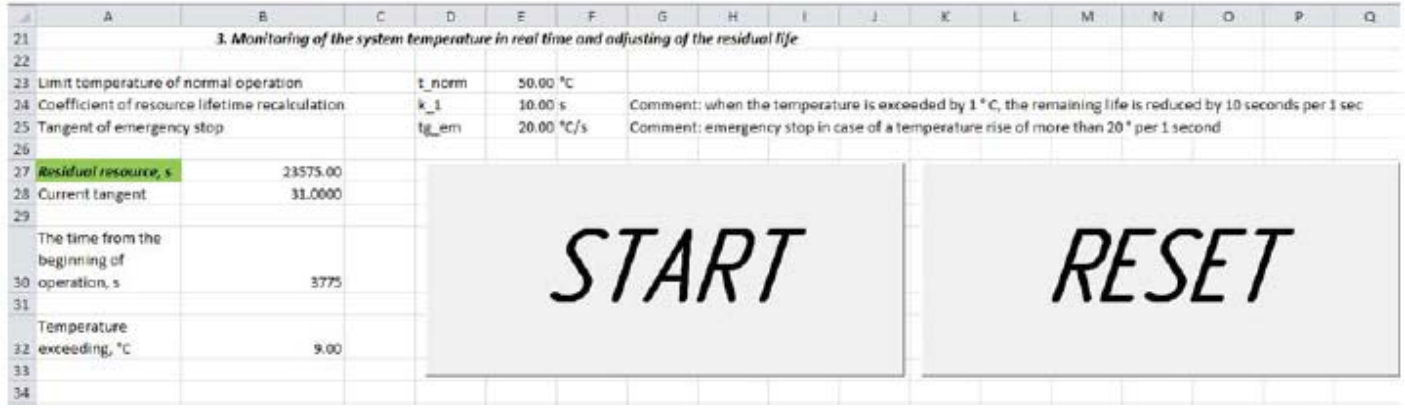

Figure 6: System temperature monitoring in a real time mode and residual resource correction

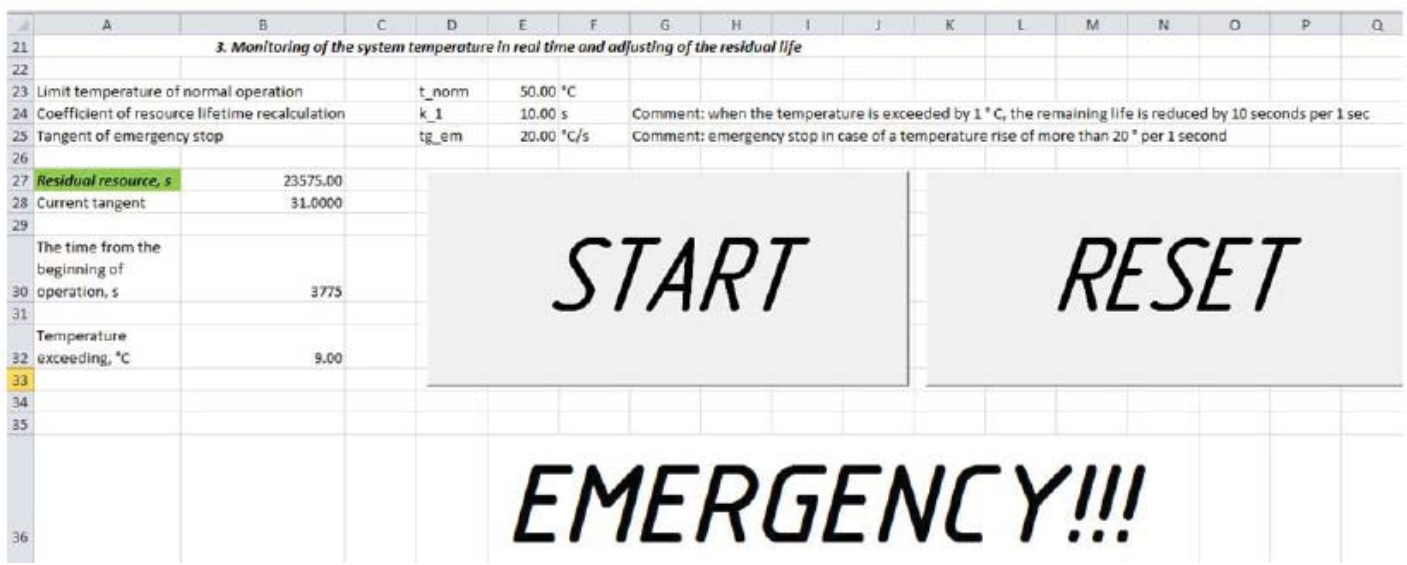

Figure 7: Result of system operation

$\Delta t$ - time step, sec.

Special attention is paid to the emergency situations when the emergency shutdown of the assembly is required. The emergencies are monitored by calculations and comparison with the threshold value of emergency shutdown tangent (rate of temperature growth):

$$
\operatorname{tg} \_ \text {em }=\left(T \_1-T \_0\right) / \Delta t \text {, }
$$

where T_0 - previous temperature value, ${ }^{\circ} \mathrm{C} ; \mathrm{T} \_0$ - current temperature value, ${ }^{\circ} \mathrm{C} ; \Delta t$ - time step, sec.

Figure 7 shows the result of system operation. 
As Figure 7 shows, the system stopped the assembly operation due to the emergency: emergency shutdown tangent grew up to the value 31 and this led to the shutdown of the system. Figure 8 shows the log file of the system operation.

The log file shows that the critical growth of temperature

\begin{tabular}{|c|c|c|}
\hline 4 & A & B \\
\hline 1 & $\begin{array}{l}\text { The time from the } \\
\text { beginning of } \\
\text { operation, } 5\end{array}$ & Event \\
\hline 73 & 3672 & Temperature exceeding: $1^{\circ} \mathrm{C}$ \\
\hline 74 & 3673 & Temperature exceeding: $1^{\circ} \mathrm{C}$ \\
\hline 75 & 3674 & Temperature exceeding: $1^{\circ} \mathrm{C}$ \\
\hline 76 & 3675 & Temperature exceeding: $1^{\circ} \mathrm{C}$ \\
\hline 77 & 3676 & Temperature exceeding: $1^{\circ} \mathrm{C}$ \\
\hline 78 & 3677 & Temperature exceeding: $1^{\circ} \mathrm{C}$ \\
\hline 79 & 3678 & Temperature exceeding: $1^{\circ} \mathrm{C}$ \\
\hline 80 & 3679 & Temperature exceeding: $1^{\circ} \mathrm{C}$ \\
\hline 81 & 3761 & Temperature exceeding: $1^{\circ} \mathrm{C}$ \\
\hline 82 & 3762 & Temperature exceeding: $9^{\circ} \mathrm{C}$ \\
\hline 83 & 3763 & Temperature exceeding: $15^{\circ} \mathrm{C}$ \\
\hline 84 & 3774 & Temperature exceeding: $5^{\circ} \mathrm{C}$ \\
\hline 85 & 3775 & Temperature exceeding: $9^{\circ} \mathrm{C}$ \\
\hline 86 & 3776 & Emergency stop!!! \\
\hline
\end{tabular}

Figure 8: Result of system operation

during an extremely short period of time led to the emergency shutdown. It is also seen that before the emergency the multiple exceeding of temperature took place and this caused the additional decrease in the residual resource. Figure 9 shows the diagram of change of residual resource depending upon the operating time of the assembly.

As the figure shows, since the start of the equipment for

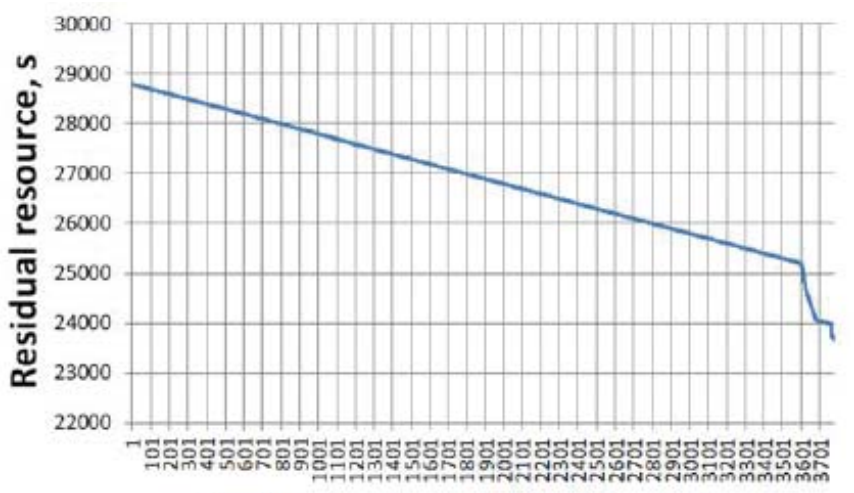

The time from the beginning of operation, $s$

Figure 9: Diagram of residual resource change

some time the assembly functioned in the normal mode: for 1 second the residual resource reduced by 1 second. On the 3601st second from the start, there were operation temperature mode disturbances and that influenced the assembly operation. Figure 10 shows the diagram of the residual resource from the 3500th second of operation.

For illustrative purposes, the temperature change diagram was added to the residual resource diagram. When temperature increased, the residual resource decreased in comparison with the normal decrease in the residual resource. The higher the temperature growth was, the

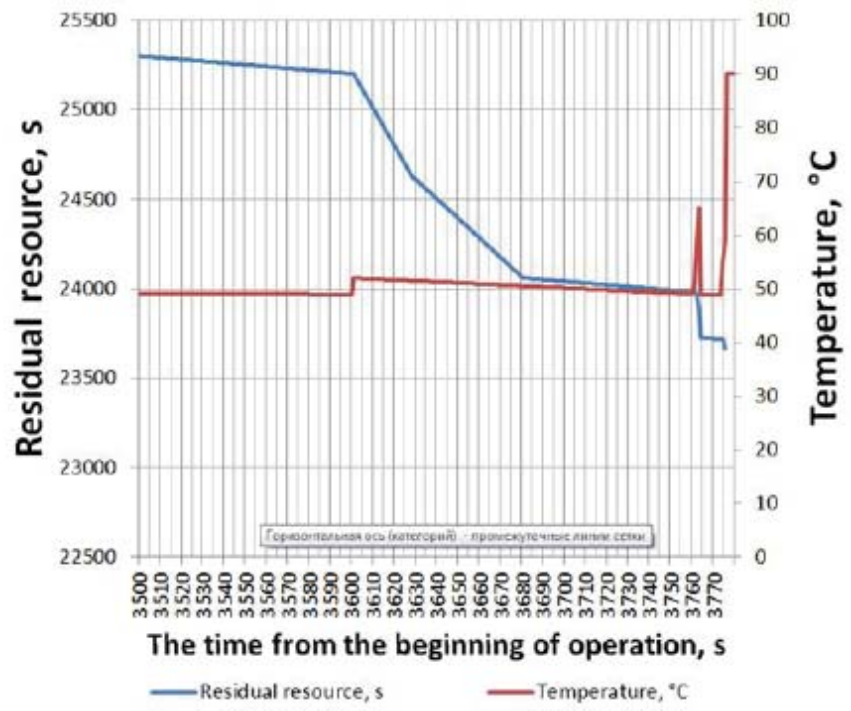

Figure 10: Diagram of residual resource change from the 3500th second

faster the residual resource decreased. Figure 11 shows the diagram of the residual resource change from the 3770th second.

As seen from the figure, the system stopped the oper-

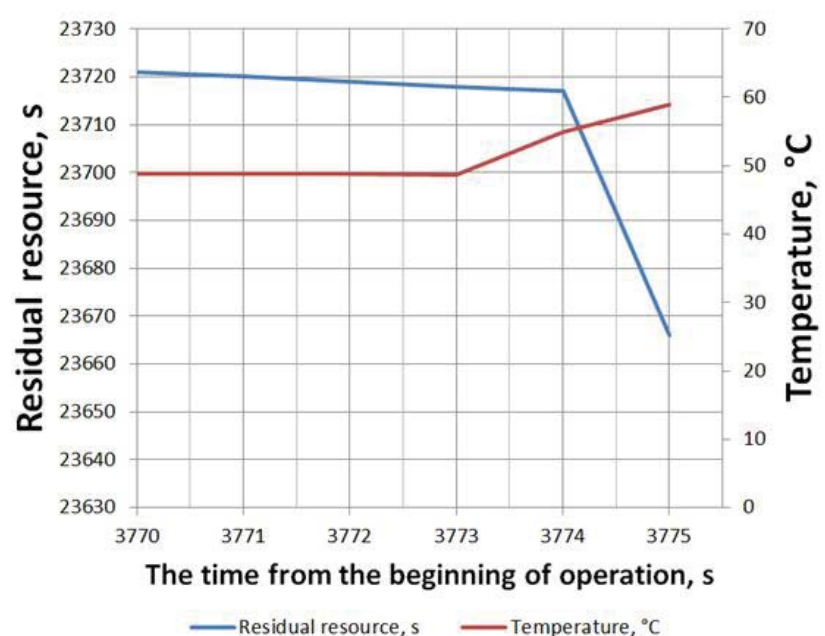

Figure 11: Diagram of residual resource change from 3770 th second

ation of the assembly from the 3775th second because the critical growth of temperature per time unit was revealed. This result demonstrates the capability of the predictive maintenance system not only to control the residual resource but to detect the emergency conditions of the equipment operation with the further shutdown.

Such emergency conditions are controlled by the registration of emergency shutdown tangent change. As mentioned above, the emergency shutdown tangent characterizes the sharp growth of temperature of the assembly that means the pre-emergency condition. Figure 12 shows the diagram of emergency shutdown tangent change and the diagram of temperature change depending upon the time from the start at last seconds.

As the figure shows, at the last seconds of the assembly 


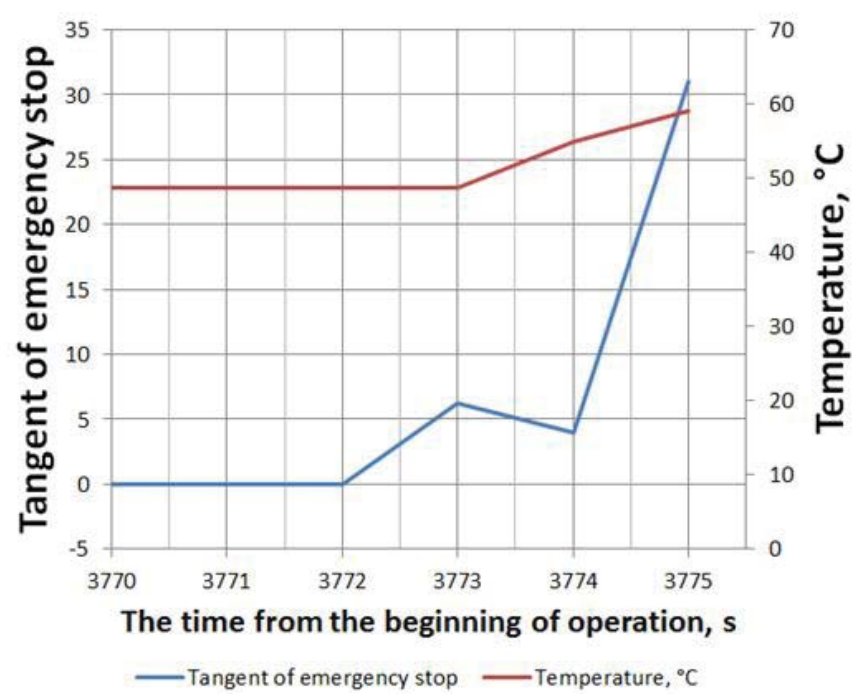

Figure 12: Diagram of emergency shutdown tangent change

operation the emergency shutdown tangent exceeded its allowed value. It signals about the sharp temperature growth. This circumstance was the reason for the assembly emergency shutdown. Figure 12 shows the diagram of emergency shutdown tangent change and the diagram of residual resource change depending upon the time from the start at last seconds.

Despite the sharp growth of emergency shutdown tan-

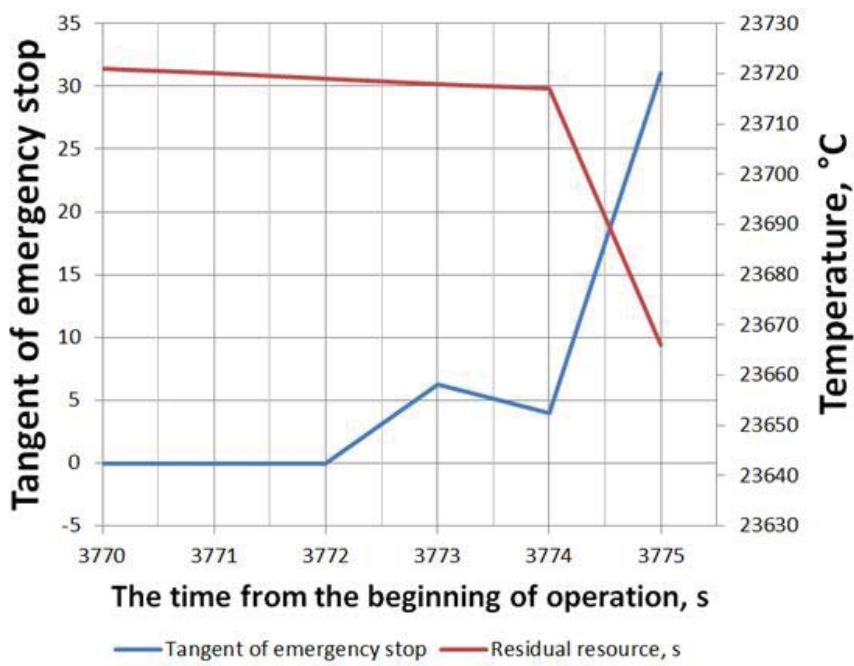

Figure 13: Diagram of emergency shutdown angent change

gent and disorderly closedown of operation, the system continued to function up to the shutdown. As the diagram shows, the sharp growth of emergency shutdown tangent caused the immediate reaction of the system in the form of the sharp decrease in the residual resource and that also was the reason for the disorderly closedown of operation. This multistage protection system allowed avoiding the serious break of the equipment and a long and expensive repair.

\section{CONCLUSION}

The considered expert system of analytical support of predictive maintenance exemplified by vacuum devices allows: calculating the residual resource of the equipment operation; analyzing the events and emergencies; correcting the residual resource of the equipment operation taking into account the external and internal factors; performing the immediate shutdown of the equipment in case of emergencies.

The introduction of this system of predictive maintenance provides the achievement of such values as a reduction of equipment downtime, a decrease in costs for equipment repair, a decrease in the number of unscheduled repairs, control of breaches of operating modes, an increase in the control efficiency of enterprise. Later it is supposed to develop this approach taking into account the microminiaturization of the elements of the intellectual controller, development of the special element base allowing performing the diagnostics of particular subsystems in a real-time mode with the intellectual functions of processing.

\section{ACKNOWLEDGMENTS}

Some results of the work were obtained with the support of the project No. 14.579.21.0142 UID RFMEFI57917X0142 within the framework of the Federal Target Program "Research and development in priority areas of development of the scientific and technological complex of Russia for 2014-2020".

\section{REFERENCES}

1. Mobley R.K. (2002). An Introduction to Predictive Maintenance, Elsevier Science.

2. Curcuru G., Cocconcelli M., Rubini R., and Galante G.M., (2017). System Monitoring and Maintenance Policies: A Review. Proceedings of The International Conference Surveillance 9, 22-24 May 2017, https:// iris.unimore.it/handle/11380/1144821

3. Rausand M., and Hoyland A. (2004). System Reliability Theory: Models, Statistical Methods and Applications, Wiley.

4. GOST R 57329-2016 (2016). Systems of Industrial Automation and Integration. Systems of Maintenance and Repair. Terms and Definitions, Publishing House of Standards, Moscow.

5. Lu C.J., and. Meeker W.Q. (1993). Using Degradation Measures to Estimate Time to Failure Distribution. Techno- metrics, 35(2), 161-174.

6. Prause G., and Atari S. (2017). On Sustainable Production Networks for Industry 4.0. Entrepreneurship and Sustainability Issues, 4(4), 421-431, https://doi. org/10.9770/jesi.2017.4.4

7. Akhter F. (2017). Unlocking Digital Entrepreneurship through Technical Business Process. Entrepreneurship and Sustainability Issues, 5(1), 36-42, https:// 
doi.org/10.9770/jesi.2017.5.1

8. Crowder M., and Lawless J. (2007). On a Scheme for Predictive Maintenance. European Journal of Operational Research, 176, 1713-1722.

9. Baptista M., Sankararaman S., Medeiros I.P. de, Nascimento C. Jr., Prendinger H., and Henriques E.M.P. (2018). Forecasting Fault Events for Predictive Maintenance Using Data-Driven Techniques and ARMA Modeling. Computers \& Industrial Engineering, 115, 41-53, https://doi.org/10.1016/j.cie.2017.10.033

10. Whitaker D.A., Egan D., O'Brien E., and Kinnear D. (2018). Application of Multivariate Data Analysis to Machine Power Measurements as a Means of Tool Life Predictive Maintenance for Reducing Product Waste, Available at: https://arxiv.org/abs/1802.08338

11. Amruthnath N., and Gupta T. (2018). A Research Study on Unsupervised Machine Learning Algorithms for Early Fault Detection in Predictive Maintenance, Available at: https://doi.org/10.13140/ RG.2.2.28822.24648

12. Vlasov A.I., Yudin A.V., Salmina M.A., Shakhnov V.A., and Usov K.A. (2017). Design Methods of Teaching the Development of Internet of Things Components with Considering Predictive Maintenance on the Basis of Mechatronic Devices. International Journal of Applied Engineering Research, 12(20), 9390-9396.

13. Yudin A., Kolesnikov M., Vlasov A., and Salmina M. (2017). Project Oriented Approach in Educational Robotics: From Robotic Competition to Practical Appliance. Advances in Intelligent Systems and Computing, 457, 83-94.

14. Odintsova A.P. (2018). Power Grid Companies Switch to Repair According to Actual Condition, Available at: https://www.clover.global/news/articles/elektrosetevyye-kompanii-perekhodyat-na-remont-po-fakticheskomu-sostoyaniyu

15. Burduk A., and Chlebus E. (2009). Evaluation of the Risk in Production systems with a Parallel Reliability Structure. Eksploatacja i Niezawodność - Maintenance and Reliability, 2(42), 84-95.

16. Bersimis S., Psarakis S., and Panaretos J. (2006). Multivariate Statistical Process Control Charts: An Overview. Quality and Reliability Engineering International, 23(5), 517-543.

17. Vermesan O., and Friess P. (2014). Internet of Things - From Research and Innovation to Market Deployment. River Publishers, pp. 106-112.

18. Goebel K., Daigle M., Saxena A., Sankararaman S., and Celaya I.R. (2017). Prognostics: The Science of Making Predictions, CreateSpace Independent Publishing Platform.
19. Bakdi A., Kouadri A., and Bensmail A. (2017). Fault Detection and Diagnosis in a Cement Rotary Kiln Using PCA with EWMA-Based Adaptive Threshold Monitoring Scheme. Control Engineering Practice, 66, 64-75.

20. Lebold M., and Thurston M. (2001). Open Standards for Condition-Based Maintenance and Prognostic Systems. Proceedings of MARCON 2001 - Fifth Annual Maintenance and Reliability Conference, Gatlinburg, USA.

21. Yang J., Chen Y., and Sun Z. (2017). A Real-Time Fault Detection and Isolation Strategy for Gas Sensor Arrays. Instrumentation and Measurement Technology Conference (I2MTC), 2017 IEEE International, 22-25 May 2017, https://doi.org/10.1109/ I2MTC.2017.7969906

22. Liggan P., and Lyons D. (2011). Applying Predictive Maintenance Techniques to Utility Systems, Retrieved from Pharmaceutical Engineering. Official Magazine of ISPE, 31(6), 1-7.

23. Du Z., Fan B., Jin X., and Chi J. (2014). Fault Detection and Diagnosis for Buildings and HVAC Systems Using Combined Neural Networks and Subtractive Clustering Analysis. Building and Environment, 73, 1-11.

24. Shafi U., Safi A., Shahid A.R., Ziauddin S., and Saleem M.Q. (2018). Vehicle Remote Health Monitoring and Prognostic Maintenance System. Journal of Advanced Transportation, Article ID 8061514, Available at: https://doi.org/10.1155/2018/8061514

25. Samanpour A.R., Ruegenberg A., and Ahlers R. (2017). The Future of Machine Learning and Predictive Analytics. Digital Marketplaces Unleashed, Springer, Available at: https://doi.org/10.1007/978-3662-49275-8_30

26. Emelianov S.G., Bakaeva N.V., and Gordon V.A. (2017). A multi-level scale of technical safety indicators of urban life support systems. Journal of Applied Engineering Science, 15(4), 459-462, https://doi. org/10.5937/jaes15-15451

27. Rakonjac I.M., Rakonjac I.M., and Gasic M.P. (2017). Comparative review of the risk assessment quantitative models for public open spaces lighting design optimization. Journal of Applied Engineering Science, 15(2), 181-186, https://doi.org/ 10.5937/ jaes 15-13926

28. Farajpourbonab E. (2017). Effective parameters on the behavior of CFDST columns. Journal of Applied Engineering Science, 15(1), 99-108, https://doi.org/ 10.5937/jaes 15-12474

Paper submitted: 25.07.2018.

Paper accepted: 28.09.2018.

This is an open access article distributed under the CC BY-NC-ND 4.0 terms and conditions. 